NBER WORKING PAPER SERIES

ZVI GRILICHES' CONTRIBUTION TO THE THEORY OF HUMAN CAPITAL

\author{
Reuben Gronau \\ Working Paper 10081 \\ http://www.nber.org/papers/w10081
}

NATIONAL BUREAU OF ECONOMIC RESEARCH

1050 Massachusetts Avenue

Cambridge, MA 02138

November 2003

Prepared for the Paris Conference on R\&D, Education and Productivity in Memory of Zvi Griliches. The views expressed herein are those of the authors and not necessarily those of the National Bureau of Economic Research.

(C)2003 by Reuben Gronau. All rights reserved. Short sections of text, not to exceed two paragraphs, may be quoted without explicit permission provided that full credit, including $(C)$ notice, is given to the source. 
Zvi Griliches' Contribution to the Theory of Human Capital

Reuben Gronau

NBER Working Paper No. 10081

November 2003

JEL No. B3, C4, C5, I2, O4

\begin{abstract}
The paper discusses Zvi Griliches' contribution to the estimation of the earning function. The topic was the central theme of Griliches' research agenda during the 70s. Griliches played a major role in the ability- schooling controversy of the time. He was instrumental in repelling the attack of the "revisionists" on the Theory of Human Capital, and the claim that the schooling effect in the earning function is merely an artifact of the true "ability" and "family background" effects. Griliches lacked at the time the proper data to prove unequivocally that the ability bias plays only a minor role in the estimation of the rate of return to schooling. He was, however, able to show that the seemingly foolproof evidence of his opponents suffers from serious biases due to the endogeneity and the measurement errors in the schooling variable. His assertion that the standard OLS estimator is biased downward, rather than upward, has been shown true by future research.

Reuben Gronau Department of Economics

Hebrew University

Mount Scopus, Jerusalem 91905

Israel

and NBER

msreuben@mscc.huji.ac.il
\end{abstract}




\section{Zvi Griliches' Contribution to the Theory of Human Capital}

\section{A. Introduction}

The acquisition and dissemination of knowledge were the central theme of Zvi Griliches' research agenda. Early in his career he stood beside Ted Schultz when Schultz ushered in the human capital revolution. He helped Schultz (1960) in his first forage in search of a solution to the "residual" puzzle (together with Gary Becker and Albert Rees), and, in turn, served on Gary Becker's NBER reading committee that approved the 1964 Human Capital manuscript. Thirty years later, at the 1993 memorial conference to his close friend Yoram Ben Porath, Griliches summarized in "Education, Human Capital and Growth - a Personal Perspective" (1997) his own venture into the field.

The reviewer of Zvi Griliches' contribution to the theory of Human Capital faces, therefore, a dual challenge. On the one hand, almost every paper Griliches has ever written bears on what he called "Knowledge Capital". To summarize his contribution implies, therefore, summarizing his career. On the other hand, Griliches on several occasions (Griliches, 1977 and 1997, Krueger and Taylor, 2000) provided a detailed and accurate summary himself. The escape route chosen by this reviewer is to narrow down the definition of the theory - focusing on Griliches' contribution to the estimation of the earning function, replacing the personal perspective with the perspective of a (hopefully) objective onlooker, with the hindsight of forty years. 
Griliches' prime interest lay in the social returns to learning. He was mainly interested in the role of education in the aggregate production function and its contribution to the explanation of the residual in growth accounting. He entered the field of earning functions only in order to improve his measure of "labor quality". The wage function to him was the analogue of a hedonic price function from which he can derive the proper weights to be used in computing the "quality index" used in the estimation of the aggregate production function (1970). Griliches joined the heated "schooling-ability" controversy of the 70s almost inadvertently. He was trying to get a better estimate of the relative contribution of schooling and ability to growth, feeling uncomfortable with the conventional Denison split of two to one, and its implication that the gross earning differential due to schooling overstates the "true" schooling effect by almost one half (Denison ,1964).

But if his entry into this skirmish was unintentional, his students drew him into it even further. William Mason's Ph.D. dissertation led to their joint study of "Education, Income and Ability" (1972), which in turn led to the first confrontation with the Pennsylvania "revisionists." Gary Chamberlain's dissertation (1975) led to the second round, the debate focusing on the conclusions that can be drawn from the economic success of brothers (Chamberlain and Griliches 1975). The debate gave birth to his Presidential address at the 1975 Third World Congress of the Econometric Society, and to the follow-up "Sibling Survey" (1979).

When the dust settled, Griliches' interest in the problems of the estimation of the earning function waned. He returned to his pastimes in the fields of productivity, $R \& D$, patents and hedonic prices. He revisited the earning function only once more 
in the mid 80s (together with John Bound and Bronwyn Hall, 1986) in a partly successful attempt to test whether families and schools treat brothers and sisters symmetrically. ${ }^{1}$

At the end of the day, Griliches always believed in measurement. If one looks for a measure of the relative importance of the research on earnings function in Griliches' research agenda, a crude measure would be the number of papers he wrote on the topic, relative to his total academic output. Browsing through his July $1998 \mathrm{CV}$, I found 11 out of 129 papers, which dealt directly with the estimation of the earning function. This is by no means a large fraction of the outpour of papers and ideas that characterized his career. Being one of the first experts on unobservables, and a pioneer of hedonic price functions Griliches would have certainly complained that the crude counting measure does not give proper weight to the aspect of quality. As, perhaps, the world's leading expert on economic gossip, Griliches would have consulted the index of citations, to find that only three of his 22 "golden hits" (papers cited more than one hundred times) are devoted to the discussion of earning functions (the 1971 ability paper with Mason, the Econometric Society Presidential Address (1977), and the Sibling Model survey (1979)). Neither can rival the popularity of his greatest hits, the 1957 Econometrica Hybrid corn paper, the 1967 Econometrica Distributed Lags survey, his 1967 paper with Dale Jorgensen on the measurement on sources of measured productivity change, and the 1984 Econometrica paper on Econometric Models for Count Data.

Given these crude measures, one may wonder whether the term "contribution" is justified in the context of the theory of human capital? Griliches himself never

\footnotetext{
${ }^{1}$ Also in this case was the study instigated by a student Ph.D dissertation (Shackett, 1981).
} 
claimed that he contributed to the development of the theory of human capital (definitely not if one uses the narrow definition of theory adopted in this paper). Still I am going to claim the Griliches played a crucial role in the development of the theory, just by being the right person, at the right time, at the right place.

To support this claim, I will provide a brief description of the state of the Theory of Human Capital in the 60s and early 70s. I will proceed describing Griliches' contribution. The fourth section will describe the aftermath of the big controversy of the $70 \mathrm{~s}$, and the paper will close with some concluding comments.

This paper, by no means, attempts to serve as a survey of the literature on earning functions. ${ }^{2}$ It suffers from an intentional selection bias, focusing on Griliches' contribution, all other contributions serving as backdrop scenery.

\section{B. Earning Functions - Childhood and Early Adolescence.}

The earning function is clearly not a new subject to economics. Its birth preceded that of the Theory of Human Capital. Clark (1937) analyzed the lifetime earnings of selected occupations in the 30s, Friedman and Kuznets (1954) analyzed the earnings of independent professions, and Blank and Stigler (1957) did it for scientific personnel. Houthakker (1959) analyzed the earning differentials associated with schooling based on the 1950 census of population.

In 1960 Miller published his paper, "Annual and Lifetime Income in Relation to Education: 1938-1959." The analysis was based on the 1940 and 1950 U.S. Census of

\footnotetext{
${ }^{2}$ Several surveys have been written on the topic over the years. It is worth noting that this is the only topic that the editors of the Handbook of Labour Economics chose to survey twice. The first edition (1986) contained an extensive survey by Robert Willis, and the 1999 third volume contained a survey of recent developments by David Carol.
} 
Population and on 1947, 1957 and 1959 Current Population Surveys. The paper was, perhaps, the last comprehensive study of earning in the U.S. that was not couched in the Theory of Human Capital jargon, and it is worth, therefore, reciting some of its results. $^{3}$

In the introduction to the paper Miller sounds almost apologetic: "Although the material gains of an education have been selected for study, the intent has not been to slur the more subtle satisfactions that come with greater educational attainment. The cultural and social advantages associated with more schooling may well be worth their cost in time, money, and effort, even if the economic advantages cease to exist." (p. 962). When presenting his results on the schooling-earning differentials, he is cautious to warn that "there is a always the possibility, indeed the probability, that the higher incomes of those with more years of schooling are due in part to differences in intelligence, home environment, family connection and other factors which result from individual differences in ability and opportunity. Therefore, to some extent, the observed relationship between schooling and earnings may be a spurious one. It is, of course, difficult if at all possible to measure the extent to which these extraneous factors enter this relationship." (p.964).

Miller's empirical findings, such as the "sheepskin" effect and the constant earnings differentials between high school and college graduates, have become the stylized facts of future research. His explanations do not sound outdated even today. According to these explanations the "sheepskin" effect reflects "selection in terms of ability"; and the constant earning differential since the pre-war era, in spite of the fast

${ }^{3}$ Miller was familiar with T.W. Schultz's writings and with early versions of Becker's theory (Becker, 1960). 
increase in the supply of college graduates, can be attributed to an increase in demand for college-labor driven by technological change. ${ }^{4}$

The fact that Miller's research has never come close to the popularity of Becker's and Mincer's work can be traced to the novel theoretical framework presented by Becker, and the imaginative interaction between theory and empirical tools which characterizes Mincer's studies.

Becker was naturally aware of the criticism that his estimates of the rate of return to college education are biased because of differences in ability between college and high-school graduates. He was the first to admit that a large fraction of the high school vs. elementary school earning differential should be attributed to differences in ability. Becker, however, went through an extensive analysis, citing several sources of data, to show that the ability bias in the estimate of the rate of return to college education is minor (1964, pp. 79-88). Among other pieces of evidence, he shows that if rank in class is used as a measure of ability the bias is of the order of magnitude of 12 percent. $^{5}$

Most skeptics seemed to be convinced by the Becker analysis. The only opposing view was that of Denison $(1962,1964)$. Following Schultz, Denison tried to separate the unexplained "growth residual" into its components. Examining the same data surveyed by Becker, he concluded that about one third of the schooling effect should be attributed to ability. In spite of this dissenting view, most Labor Economics

${ }^{4}$ Some of the insights in Miller's paper, for example, the changing composition of the "ability pool" of different schooling groups over time, are popular topics of research even today.

${ }^{5}$ Another piece of evidence is based on the comparisons of high school graduates with college dropouts, since the two groups seem to have similar class ranks in high school, and similar scores on IQ tests. Comparing the rates of return to college dropouts and college graduates the bias is estimated 
practitioners accepted Becker's conclusion that "it may be concluded that, even after adjustment for differential ability, the private rate of return to a typical white male college graduate would be considerable" (1964, p. 88).

The following decade can be considered as the heydays of the Theory of Human Capital, and the earning function estimates. Ben Porath (1967) employed an elegant optimum control model to explain the concavity of the age-earning profile. Mincer $(1962,1974)$ demonstrated how the on-the-job training model could serve as a powerful tool in analyzing the earning distribution. Becker (1967) presented a more comprehensive model where the demand for schooling and the supply of funds determine simultaneously the level of schooling and earnings. In this model "ability" explains the interpersonal variation in demand, and "opportunities" explain the variation in supply. The covariation of these factors determines the distribution of earnings. Parsons (1972) borrowed the concept of "specific human capital," to explain mobility patterns and the unemployment structure. Each of these studies gave rise to additional studies, building on the foundations of their predecessors, leading an even "jaundiced" critic such as Mark Blaug to admit "that the human-capital research program has displayed a simply amazing fecundity, spawning new research projects in almost every branch of economics." (1976, p. 833).

The "ability bias" issue remained dormant for the rest of the $60 \mathrm{~s}$. The major reason for this loss of interest was, perhaps, the dearth of data. The only two new samples that included direct measures of ability were clearly non-representative, and could not shed

to be about one-third. In an early paper on the social rate of return to college education (1960) Becker concludes that ability differentials account for 2 out of the 11 percentage points return. 
any new light on the phenomenon. ${ }^{6}$ It was Griliches who reawakened the issue when he tried to "appeal" Denison's conclusions. ${ }^{7}$ His 1970 survey signaled a new wave of studies focusing on the ability-schooling interaction. This wave was rekindled by the availability of new sources of data containing direct observations on IQ test scores, schooling, and earning. Some of these studies were written by Griliches himself (with collaborators), but many came from other directions.

The first of these studies were John Hause's. In his 1972 paper he examined four bodies of data, finding strong evidence of complementarity between ability, schooling and post-school experience. Ability differentials have no effect on earnings at the lower schooling levels, but have a significant effect at higher schooling levels, this effect becoming more pronounced the larger the worker's labor force experience. Consequently, the ability bias in the estimate of the rate of return of college education is insignificant, when the earnings are observed at the early stages of one's career, and are of moderate importance (3-18 percent) when one examines the earnings of prime age workers.

One of the bodies of data surveyed in the Hause 1972 paper was the NBER-Thorndike sample. The sample consisted of World War II U.S. Air force volunteers who were reinterviewed in 1955 by Robert Thorndike and Elizabeth Hagen. The 1943 data containing the scores on a battery of 17 tests was complemented in 1955 by additional tests and data on earnings. Paul Taubman and Terence Wales who discovered the data

\footnotetext{
${ }^{6}$ Ashenfelter and Mooney (1968) used a sample derived from the upper tail of the ability distribution (Woodrow Wilson Fellowship holders) only to find that the ability bias is miniscule. Hansen, Weisbrod and Scanlon (1970) derived their sample from the opposite tail of the distribution (sampling military rejects) and found that introducing AFQT scores into the (linear) wage equation reduces the schooling coefficient significantly.

${ }^{7}$ See next section.
} 
enlisted the help of the National Bureau of Economic Research to re-interview about 6,000 of these men in $1969^{8}$. The sample's selection criterion resulted in an overrepresentation of high ability - highly educated men, but it was at the time, both in terms of quality and in terms of size, by far superior to any other similar body of data ${ }^{9}$. Taubman and Wales analyzed their sample and reach somewhat different conclusions from those reached by Hause. Like Hause, they found that ability has little effect on starting salaries but that its effect grows over time; growing, perhaps, even more rapidly for those with graduate training and high ability. However their estimate for the ability-bias was significantly higher than that of Hause ${ }^{10}$. They found a bias of $15-$ 25 percent. When one controls also for age, the ability bias increases to 30-35 percent. Though this estimate was arrived controlling for age rather than work-experience, this is the estimate Taubman chose as the "true" ability-bias. ${ }^{11}$ Not less disturbing to the standard theory was the conclusion that "it is almost certain that, for those in this cohort who are at least high-school graduates, ability is a more important determinant of the range of the income distribution than is education" (1974, p.9).

To an innocent bystander like Clark Kerr" , "potentially even more damaging to human-capital theory (was) the Taubman-Wales finding that, for those with some

\footnotetext{
${ }^{8}$ Paul Taubman and his collaborators were pioneers in the field of primary data collection, preceding by more than a decade the wave of the data collection of the 90 's.

${ }^{9}$ The Taubman-Wales sample consisted of 4,440 observations. John Hause used a sub-sample of 2,300 observations.

${ }^{10}$ The Taubman-Wales analysis differs from the Hause study in several respects: 1) it uses a larger sample, including self-employed; 2) the "ability" variable is defined differently; and 3) it uses a different mathematical specification of the earnings function.

${ }^{11}$ See Taubman's comments on the Griliches-Mason paper (1972), and Juster's summary of the Taubman-Wales findings (1974).

${ }^{12}$ Clark Kerr, the ex-chancellor of the University of California, was the Chairman of the Carnegie Commission on Higher Education that co-sponsored the Taubman-Wales study. The citation is taken from his introduction to the book (1974).
} 
college or a B.A., a substantial part of the earnings advantage associated with education was attributable to "screening," that is, the requirements or preferences of employers for those with a college education". It is doubtful whether the supporting evidence for this far-reaching conclusion- the over-representation of college graduates in the better paying occupations- would, today, be regarded as a threat to the Theory of Human Capital. What seemed threatening at the time was the avalanche of elegant theoretical paper relating to schooling as a signaling device. This fad started with Spence's Ph.D. dissertation $(1973,1974)$ followed by Arrow (1973), Stiglitz (1975), and Riley $(1975,1979)$. The common feature of these models is the argument that schools do not "produce" any "market-oriented skills", but just aid employers who try to screen their workers according to "ability." The more "able" workers are also more efficient at producing "schooling," and hence will "purchase" more "schooling" to signal their higher ability. The perplexing feature of this theory is that its empirical implications are almost indistinguishable from the "traditional" theory of Human Capital. Taubman and Wales, however, claimed that their results could serve as support of the "Screening Theory," and a refutation of the traditional theory.

To better understand the importance and timeliness of Zvi Griliches' Presidential Address, it is worth reproducing some of the points of criticism raised by Mark Blaug in his "slightly jaundiced" survey of "The Empirical Status of Human Capital Theory" written on the eve of the Econometric Society meeting. Blaug reserved special scorn to the estimation of the standard Mincer-type earning function.

"No wonder the bulk of empirical work inspired by the human-capital framework has taken the form of regressing the earnings of individuals on such 
variables, as native ability, family background, place of residence, years of schooling, years of work experience, occupational status, and the like - the socalled "earnings function." It is sometimes difficult in all this research to see precisely what hypothesis is being tested, other than that schooling and work experience are important and that native ability and family background are not”. (1976, p.832).

In his summary Blaug has to admit

"We must give credit where credit is due. The human-capital research program has moved steadily away from some of its early naive formulations, and has boldly attacked certain traditionally neglected topics in economics, such as the distribution of personal income. Moreover, it has never entirely lost sight of its original goal of demonstrating that a wide range of apparently disconnected phenomena in the world are the outcome of a definite pattern of individual decisions, having in common the features of forgoing present gains for the prospect of future ones. In so doing, it discovered novel facts, such as the correlation between education and age-specific earnings, which have opened up entirely new areas of research in economics. Whether this momentum can be maintained in the future is, of course, anybody's guess, but it is noteworthy that the screening hypothesis first emerged in the writings of adherents to the human-capital research program, and to this day the most fruitful empirical work in the testing of credentialist hypotheses continues to emerge from the friends rather than the enemies of human-capital theory."

But this did nothing to dampen his criticism

"We are thus condemned to judge the human-capital research program largely in its own terms, which is strictly speaking impossible - even the flatearth research program, judged in its own terms, is not faring too badly! There are certainly grounds for thinking that the human-capital research program is now in something of a "crisis.... Its rate-of-return calculations repeatedly turn up significant, unexplained differences in the yields of investment in different types of human capital, but its schooling-model explanation of the distribution of earnings nevertheless goes on blithely assuming that all rates of return to human-capital formation are equalized at the margin. Worse still, is the persistent resort to ad hoc auxiliary assumptions to account for every perverse result, culminating in a certain tendency to mindlessly grind out the same calculation with a new set of data which are typical signs of degeneration in a scientific research program."

The Presidential Address did not try to cope with all the points of criticism raised by

Blaug. It focused on what Griliches regarded as the greatest empirical challenge - the 
most recent estimates of the ability bias, in the hope that disproving the "revisionists" on this critical issue will dispel at least some of the felling of "crisis."

By the time Griliches delivered his Presidential Address, the "revisionists" were already preparing their next "assault," introducing into the "battlefield," what they must have considered the "ultimate weapon" - the twin data. Twin data were not alien to social scientists. Jensen and his co-authors were using this type of data almost a decade before (1967) to isolate the role of heredity, environment and luck. Taubman and his coauthors stumbled on the NAS-NRC sample of twins almost accidentally. But once their students awakened them to the existence of the data, they realized immediately their importance to the ongoing debate.

Taubman published his first paper on the topic in 1976, and the summary of his study in 1980. A new term was introduced into the econometric and the labor economists' jargon-kinometrics, and in 1977 the first conference was held on the findings and the econometrics of sibling data.

The implicit assumptions driving the twin model were simple. In its simplest version (Willis, 1986) the twin model assumes that the unobservable variables can be divided into two parts: "heredity" (or, "genetic") variables and "environmental" variables. Identical twins (MZ) share the same hereditary and environmental variables. Hence, running the earning regression "within" MZ cells (where the dependent variable is the difference in earnings and the explanatory variable the difference in schooling) one can isolate these effects, and generate the "true" schooling effect. Moreover, since non-identical twins (DZ) share only the same environmental variables, the same "within" regression run in the DZ sample will generate a schooling 
coefficient that reflects both the "true" schooling effect and the hereditary effect. A comparison with the MZ results yields, therefore, the net hereditary effect. Finally, the comparison of the standard regression for unrelated workers with the $\mathrm{DZ}$ regression allows the isolation of the environment effects. ${ }^{13}$

A sub-sample of the twin sample used by Taubman et al, contained direct information on the respondents' cognitive skills. Controlling for this variable in a standard earning-schooling regression for mature workers reduced the schooling coefficient by 35 percent. Rerunning the regression for the whole sample on the individual data (not controlling for cognitive skills), the crude schooling coefficient was found to be 0.08 . Controlling for observed family background variables, the coefficient declined to 0.07 . The "within" DZ regression, controlling for unobserved common environment, yielded a coefficient of 0.06 , and the "within" MZ regression yielded an estimate of the "true" schooling coefficient of 0.025 . According to these findings, the "true" ability bias was, therefore, about two- thirds of the standard estimate!

Taubman and his co-authors (Behrman et al., 1980) were quick to draw their policy recommendations. They concluded " that policies to equalize schooling will have little effect on inequality of earning or status. Family plays a major role in generating inequality of education, occupational status and earnings. It appears, however, that most of the family effects arise out of genetic endowment; thus, policies designed to equalize opportunity defined solely in terms of family environment will leave substantial inequality of outcomes within a generation." (p.32). The only

${ }^{13}$ More complex models and their implicit econometric assumptions are discussed in Goldberger (1977). 
message of hope the authors had for their readers was in terms of intergenerational mobility: Eliminating all environmental differences should eliminate almost the whole intergenerational correlation in earning. For most readers that would be a small solace!

\section{Griliches Steps In.}

Griliches opened his academic career with a series of blockbusters - his studies of hybrid corn $(1957,1958)$. As he tells his story (Krueger and Taylor, 2000) he knew relatively little about agriculture, but he learned from his personal experience the importance of learning. The problems associated with diffusion of new knowledge were hand-tailored for his talents. From there, it was only a small step to a series of studies in which he tried to isolate the contribution of education and investment in R\&D to measured productivity in agriculture (1963a, 1963b, 1964). The major finding of these studies was that the "labor quality" measure (i.e., the education of farm labor) enters the aggregate agriculture production function with a coefficient which is not significantly different from that of the labor variable.

Hence, one can combine both the quantity and quality dimensions of labor into one variable. He also found that though the elasticity of output with respect of R\&E expenditures (research and extension services) is rather low (about 5 percent), the social rate of return to these expenditures is extremely high (about 300 percent).

The next natural step was a territorial expansion into manufacturing (1967a, 1968), and his work with Dale Jorgensen (1966, 1967b). In 1968 when the National Board of Economic Research convened its annual conference on Income and Wealth, focusing on the topic of "Education, Income and Human Capital," Griliches 
was the natural candidate to present the survey on the "Role of Education in Production Functions and Growth Accounting” (1970).

After discussing the different ways "quality" can be introduced as a parameter in the production function, the paper discusses to the problems of aggregation. The search for a common denominator of the different kinds of labor (distinguished by occupation, schooling, race, gender, location, etc.) lead Griliches to conclude: "the next small step is obviously not in the direction of a very large number of types of labor, but rather towards the question of whether there are a few underlying relevant "dimensions of labor," which could explain, satisfactorily, the observed diversity in the wages paid to different "kinds" of labor. The obvious analogy here is to hedonic or characteristics approach to the analysis of quality change in consumer goods... One can identify the "human capital" approach as a onedimensional version of such an approach” (1970, p. 90).

In his basic equation

$$
\text { (1) } w_{i}=w_{0}+r H_{i}+u
$$

the wage of $\left(\mathrm{w}_{\mathrm{i}}\right)$ consists of the remuneration for "raw labor" $\left(\mathrm{w}_{0}\right)$ and the "rental value of units of human capital $(\mathrm{r} \mathrm{H})$. The problem, of course, with this analysis is that whereas car fins and engine power are measurable, human capital units $\left(\mathrm{H}_{\mathrm{i}}\right)$ are unobserved. $^{14}$

The next section is named "ability". Surprisingly, this section, which is somewhat tangential to the issues of growth accounting, turns out to be the central

\footnotetext{
${ }^{14}$ Griliches was, of course, aware of this distinction. He even suggested that "if one is willing to assume that the implicit prices ( $w_{0}$ and $r$ ) are constant, and one has repeated observations for a given (observation), one can use such a framework to estimate the unobserved "latent" $\left(H_{i}\right)$ variable" (ibid.)
} 
part of the survey, occupying almost one-third of its length. What must have triggered the analysis was Denison's 1964 suggestion that about one-third of the observed income-by-schooling differential should not be attributed to learning but to natural talent. Griliches resented this assertion not just in the context of the secular contribution to growth, but primarily because of its implication for the estimates of the rate of return to schooling derived from cross-section surveys.

Griliches' starting point is the standard model

(2) $y_{i}=\beta_{0}+\beta_{1} S_{i}+\beta_{2} A_{i}+u$,

where $\mathrm{y}$ denotes income, $\mathrm{S}-$ schooling, $\mathrm{A}-$ ability, and $\beta_{1}$ and $\beta_{2}$ are assumed to be positive. The crude schooling regression coefficient $\left(b_{\mathrm{ys}}\right)$ is upward biased as long as the correlation between schooling $\mathrm{S}$ and the omitted variable $\mathrm{A}$ is positive. (3) $\mathrm{Eb}_{\mathrm{ys}}=\beta_{1}+\beta_{2} \mathrm{~b}_{\mathrm{AS}}>\beta_{1} \Leftrightarrow \mathrm{b}_{\mathrm{AS}}>0$.

But is this so? Griliches had his doubts about the direction and size of the bias, and its interpretation. As he phrased it: "Much of measured ability is the product of "learning" even if it is not the product of "schooling." Often what passes as "ability" is actually some measure of "achievement," and the argument could be made that it, in turn, is determined by a relation of the form

(4) $\mathrm{A}=\alpha_{0}+\alpha_{1} S+\alpha_{2} Q S+\alpha_{3} L H+\alpha_{4} G+v$, where $S$ is the level of schooling, QS is the quality of schooling, LH are the learning inputs at "home," and G is the original genetic endowment." Here in a nutshell are the four factors the search for whom will preoccupy Griliches throughout the coming decade. 
The total effect of "reproducible" human capital (including the quality of schooling and learning at home) equals

(5) $\beta_{1}+\beta_{2}\left(\alpha_{1}+\alpha_{2} b_{\text {QS.S }}+\alpha_{3} b_{\text {LH.S }}\right)$,

where the b-terms in the parentheses are the regression coefficient of school quality (QS) and home-learning (LH) on years of schooling (S). Comparing equation (2) with equation (4), it is not clear whether the simple regression coefficient $b_{\mathrm{ys}}$ does in fact overstate the total effect.

Griliches had also his doubts about the relative magnitude of the auxiliary regression coefficient $b_{\mathrm{AS}}$. Ability may interact with schooling and have a significant effect on earnings at high level of schooling, but $b_{\mathrm{AS}}$ itself may be quite low. Furthermore, the interaction between schooling and ability (or measured intelligence) is not a one-way relationship. It can be affected by schooling and the person's environment, and, in turn, it affects the amount of learning achieved in a given schooling situation. The more intelligent student is endowed with a greater initial endowment of knowledge and is more efficient in acquiring additional knowledge. "One might venture to define the gross output of the schooling system as ability," and at least part of the apparent returns to ability should be imputed to the schooling system. This part should be quite large assuming, as Griliches did, that ability is not the binding constraint in the determination of schooling levels.

Griliches returned to the data examined by Denison and could not find evidence to justify the large correction recommended by him. A large fraction of Denison's ability correction is ascribed to father's occupation and regional income 
differentials, ${ }^{15}$ and " less than one-third of the "one-third" adjustment is related conceptually to ability per se." (ibid., p. 103). Griliches stuck to this estimate of a "10 percent adjustment" throughout his career!

To support his own argument concerning the small magnitude of the ability bias he cites a Swedish study (Husen 1968). The study included, in addition to the data on the earnings at the age of 35 by schooling, the IQ tests at the age of 10 of the men interviewed. It showed that, though the IQ explained almost 25 percent of the variance of log earnings, the bias introduced by its omission is minimal (4 percent).

For the next round, the 1971 University of Chicago workshop on "Investment in Education: The Equity-Efficiency Quandary, ${ }^{, 16}$ Griliches came already equipped with the data he was looking for. The data were based on a 1964 sample of U.S. military veterans. ${ }^{17}$ The 1964 CPS data on earnings and schooling were collated with their military records containing information on their pre-military schooling levels, and their scores on the Armed Forces Qualification Tests (AFQT), and socio-economic background. The sample consisted of about 1500 fully employed men in the age group 21 to 34 .

About one-third of the men in the sample continued their schooling after the military career. The variable 'years studied after the military' played a major role in the analysis because it allowed the authors to break the alleged simultaneous relationship between 'ability' and 'schooling'. Since 'ability' (i.e., AFQT scores)

\footnotetext{
${ }^{15}$ Denison's conclusions are based on tables where the proxy for ability is father's occupation. Griliches argues that father's occupation is positively correlated with more learning at home and with a higher quality of schooling. At least the second factor should be subtracted from the schooling effect. ${ }^{16} \mathrm{An}$ early version of the paper was presented in a conference on Structural Equation Models in Madison (Wisconsin) in November 1970.
} 
was measured prior to the military career, and schooling related to post-military schooling, the direction of the causality is unambivalent. Griliches and Mason noted that introducing the AFQT scores into the log-linear equation reduced this schooling coefficient by 10 percent. The introduction of post-military schooling, together with father's occupation and pre-military region of residence, reduced the coefficient by 12 percent.

Using as a measure of schooling the variable 'total schooling' (rather than 'post-military schooling'), the ability bias increases considerably. ${ }^{18}$ To explain the sensitivity of the results to the measure of schooling, the authors enlisted an error of measurement model, where "education" is measured with an error

$$
S_{i}=S_{i}^{\prime}+S_{i}^{\prime \prime} \text {, and } \operatorname{cov}\left(S_{i}^{\prime}, S_{i}^{\prime \prime}\right)=0
$$

where $\mathrm{S}^{\prime}$ is measured schooling and $\mathrm{S}$ " is the measurement error. The authors called this error 'schooling quality' and assumed $\operatorname{cov}(\mathrm{S}$ ", $\mathrm{A})>0$, i.e., the more able enjoy higher school quality. The partial regression coefficient of earnings on measured schooling, controlling for ability, equals

$$
B_{Y S^{\prime} A}=\beta_{1}\left[1-\left(b_{S^{\prime \prime} A} b_{A S^{\prime}}\right) /\left(1-r_{A S^{\prime}}^{2}\right)\right]
$$

Thus, if the assumption that $\mathrm{b}_{\mathrm{S}^{\mathrm{A}} \mathrm{A}}>0$ holds, the partial regression coefficient will understate the "true" schooling coefficient $\beta_{1}$. The risk of this bias is reduced if

\footnotetext{
${ }^{17}$ The data were provided by his collaborator, William Mason, who used them in his (sociology) Ph.D. dissertation.

${ }^{18} 28$ percent where both 'ability' and family background are omitted from the equation, and 15 percent when only 'ability' is omitted.
} 
one uses as the schooling variable - 'incremental schooling' (post-military schooling) instead of 'pre-military' or 'total schooling, 19

The authors expanded the model to incorporate errors of measurement in ability, embedding them in a framework of a recursive model. In this model measured "background factors" and unobservable heredity feed into ability and 'initial schooling', 'initial schooling' and 'initial ability' determine the changes in ability, which, in turn, determines earning. The more complex model and estimation procedure (two-stage-least-square) did not, however, lead to any additional insights into the schooling-ability relation.

The discussant of the Griliches - Mason paper at the Chicago workshop was Paul Taubman. This was the beginning of a decade that can only be characterized by the words of the song "Everything You Can Do - I Can Do Better!"

Taubman thought his work with Wales had not been given sufficient credit, and he regarded (rightly) his NBER-Thorndike data to be superior to those used by Griliches and Mason. However, the only explanation he could provide for the difference in the findings was the linearization of the schooling variable (i.e., the use of a continuous schooling variable instead of dummy variables) and the use of the total AFQT scores rather than the individual tests ${ }^{20}$.

The next round was again set by one of Griliches' students. This time it was Gary Chamberlain, and his Ph.D. dissertation, "Unobservables in Econometric

\footnotetext{
${ }^{19}$ The authors ignore the possibility that the pre-military AFQT score affects the draftee's millitary career and his decision to continue his schooling. Thus even if $b_{S^{\prime \prime}}$ is smaller for incremental schooling, $\mathrm{r}_{\mathrm{S}^{\prime} \mathrm{A}}^{2}$ can be larger.

${ }^{20}$ The Griliches - Mason AFQT variable did not contain the breakdown for the different tests.
} 
Models" (1975). One way to isolate the unobservable variables requires the use "multi-dimensional" data. The standard procedure would be the use of panel data, where the time dimension allows for the isolation of the unobservable "individual" effects. Panel data in the early 70s were still rare, and covered only a short-time span. Perhaps more important, panel data do not contain, in general, sufficient temporal variation in schooling - the variable the research focused on.

Chamberlain and Griliches (1975) reverted, therefore, to siblings' data as a source that will allow them, hopefully, to control for family environment. The idea of choosing brothers to get a better measure of the effect of schooling was not novel $^{21}$, what was novel was the set of econometric tools brought to the analysis.

Two fundamental changes were introduced in the model. Whereas, in the 1970 paper 'ability' was defined as the endogenous variable - being the "gross output of the schooling system," in the 1975 schooling is affected by ability. Equation (3) is replaced by an equation of the type

(8) $S=\gamma_{0}+\gamma_{1} A+w$;

making S an endogenous variable. The "repeated" observations (i.e., the observation for the two brothers) are the basis of the variance-components model

$$
A_{i j}=f_{i}+a_{i j} \text {, }
$$

where $i$ denotes the family, $j$ the sibling, $f_{i}$ is the family component and of $a_{i j}$ the individual component.

\footnotetext{
${ }^{21}$ The Gorseline data used by Chamberlain and Griliches had already been discussed by Becker (1964).
} 
Unfortunately, the data used by Chamberlain-Griliches (1975) could not bear the weight of the econometric method. To demonstrate the usefulness of their new tool, the authors reverted to a small sample of brothers (127 pairs) already analyzed by Gorseline (1932). The limitations of the data forced Chamberlain and Griliches to be very careful in the phrasing of their conclusion "that at least in 1927, in Indiana, differences in parental background were not an important source of bias in the estimated returns to schooling" (1975, p. 429). An even more elaborate estimation method led to a similar conclusion - i.e., that the unobserved variable affected income, but had only a negligible effect on schooling. ${ }^{22}$ The authors are forced, therefore, to sum up this empirical attempt with a retraction: "So our prior expectation that the unobservable which we call "ability" would be an important determinant of schooling and interpretable as IQ or family wealth is not born out by the data." (ibid.,p.431). Additional toying with the model led only to new question marks, ${ }^{23}$ generating a typical Griliches summary: "From a substantive point of view, the new econometric methods did not produce results which differed greatly from those based on simpler methods. This is either satisfying or disappointing, depending on one's point of view. An elaborate procedure, designed to detect possible sources of bias, yielded little evidence of such bias. It is quite likely that important unobserved variables have been left out from our schooling-achievement model, but they are not of the type one usually associates with notion of intellectual "ability."

\footnotetext{
${ }^{22}$ This was true both for the magnitudes of the coefficients and to the fit of the equations.

${ }^{23}$ The initial variance-component model relied heavily on the assumption that economic success ( $y$ in equation 1) has two independent manifestations: income and occupational status (i.e., the random components $(\mathrm{u})$ in the two structural equations for $\mathrm{y}$ are uncorrelated). The lack of correlation was the
} 
The contribution of the Chamberlain-Griliches 1975 paper is, therefore, confined mostly to the econometric technique, and little insights were gained concerning the ability-schooling interaction. The same can be said about its twin - the ChamberlainGriliches 1977 paper at the conference of Kinometrics. ${ }^{24}$ While Chamberlain and Griliches were toying with their poor quality sample of brothers, Taubman came up with his sample of twins (1976, and Behrman et al. 1980).

Griliches chose the state for the next confrontation with the "revisionists." It was the Third World Congress of the Econometric Society, which convened in Toronto in August 1975. Zvi Griliches delivered the Presidential Address. He was the first economist engaged in the "new" Labor Economics research to be elected as President of the Society, ${ }^{25}$ and the stature of the presidency clearly added weight to the message.

The recursive model presented in the paper was a combination of the GrilichesMason and the Chamberlain-Griliches models. Given the limitations of the data (the NLSY sample ${ }^{26}$ ), the conclusion that the "overall direct contribution of "ability," as measured by test scores, to the explanation of the variance of individual expected earnings is quite small, on the order of.01," has to be treated with care.

More important was the digression to the topic of errors of measurement in schooling and their impact on the estimated rate of return. Griliches had already

identifying assumption for the error component $\sigma_{\mathrm{f}}^{2} / \sigma_{\mathrm{a}}^{2}$. The data clearly rejected the independence assumption forcing the authors to replace the estimate of $\sigma_{\mathrm{g}}^{2} / \sigma_{\mathrm{a}}^{2}$ with simulations.

${ }^{24}$ In the 1997 paper Chamberlain and Grilishes used a sample, employed by Griliches before (1976) of 282 brothers derived from the 1966-69 rounds of the NLSY (the National Longitudinal Survey of Young Men). In contrast to the Gorseline data this survey had direct observations on the IQ scores (it even had the scores of tests conducted at two different points of time), but it lacked data on the most important variable - earnings, because most brothers were still too young to participate in the labor force. The authors had, therefore, to replace this crucial information with imputations.

${ }^{25}$ The only other President of the Society who contributed to Labor Economics is Marc Neslove.

${ }^{26}$ See footnote 23 . 
touched upon this topic before, in his paper with Mason, ${ }^{27}$ but here, for the first time, he demonstrated that under reasonable assumption concerning the magnitude of the ability effect and the schooling-ability correlation, the downward bias due to measurement errors, when one controls for ability, can be as large as the upward bias, when ability is omitted from the equation

$$
-\lambda \beta_{1} /\left(1-\mathrm{r}_{\mathrm{AS}}^{2}\right) \cong \beta_{2} \mathrm{~b}_{\mathrm{AS}}
$$

where $\lambda=\sigma_{\mathrm{S}^{\prime \prime}}^{2} / \sigma_{\mathrm{S}}^{2}$ is the error component in schooling, and the $\beta_{\mathrm{i}}$ are the schooling and ability effects (see equation 1). Additional variables in the earning function can exacerbate this problem.

The final section of the paper discussed the endogeneity of the schooling variable. The problem itself was not new to readers of Griliches' earlier papers (see equation 7), or to practitioners in the field. ${ }^{28}$ The Presidential Address helped in moving the problem to the center-stage. ${ }^{29}$ Griliches mentions two sources of this endogeneity:

a. The positive correlation between the ex-post random component in earnings and the ex-ante random component in anticipated earnings that affect the schooling decision.

b. The effect unobserved ability has on both schooling and earnings. Citing Rosen, Griliches showed that one could not rule out the possibility that ability has a negative effect on schooling, and that the simple OLS schooling coefficient suffers, therefore, from a serious downward bias ${ }^{30}$.

\footnotetext{
${ }^{27}$ In the Griliches-Mason (1972) paper the authors preferred to call the error "school quality".

${ }^{28}$ Griliches himself attributes the discussion to his readings in Becker and Mincer and his discussions with Sherwin Rosen.

${ }^{29}$ Endogeneity is the central theme of both surveys on the earning function in the Handbook of Labor Economics (1986, 1999), attesting to its importance.

${ }^{30}$ If the more able are endowed with a higher initial stock of human capital they may spend fewer years in school. This may also be true if the more able are faster learners.
} 
The Presidential Address did not cope directly with the challenge posed by the Taubman twin studies. In the 1977 conference on Kinometrics it was Goldberger who carried the skeptics' flag. It took Griliches another two years to prepare his response (1979). The Sibling Models "Partial Survey" is a scathing attack on the "within" family regression as a device to neutralize family effects. Griliches goes through a series of examples where a "within" family regression may inflate biases instead of eliminating them. The most serious of these cases is again the case of errors of measurement in the schooling variable. The lengthy list of possible biases and identification problems can be regarded as aimed at Taubman and his co-authors, but it contains more than a grain of self-criticism: "In short, one cannot really hope to estimate very complicated models, which allow for a variety of unmeasured influences. Either one has better data in which the errors-in-variables problem does not arise, or one has to limit oneself to a very short and specific list of left-out variables and ways in which they affect the model. Latent-variable models and estimation techniques are no substitute for good data and substantive restrictions” (1979, p. S48).

His criticism of the "twin models" echoes that of Goldberger:

"On observed variables, $M Z$ s (identical twins) are more similar than DZs (fraternal twins). On the latent variable, genotype, it is known that MZs are more similar than DZs. On the latent variable, environment, it is not known whether MZs are more similar than DZs. Assume that they are not. Then attribute the excess observed resemblance of MZs to their excess genetic resemblance, thus estimating the role of heredity. That is the gist of the twin method. Since the equal-environmental-correlation assumption is questionable, the estimates produced by the method should be viewed skeptically" (Goldberger ,1997, p. 299).

The final section of the survey emphasizes the importance of family decisions as a determinant of siblings' schooling and intra-family inequality in earning. Griliches 
expressed his belief that families act as income equalizers, but admits that much more has to be learned in order to understand the effect of family background on their children's economic success. ${ }^{31}$

The survey’s “Provisional Summary” reads as Griliches' summary of his ten-year excursion into the field of earnings functions. It is worth citing it verbatim:

"The following appears to be a fair summary of the state of our knowledge on this topic: Measured parental characteristics (except for race and region) appear to affect earnings primarily via their effect on the level of achieved schooling. The market does not appear to pay for them directly. Unmeasured "family" characteristics have a substantial though not large effect on the variance of earnings (10-15 percent), but their interpretation is obscure. In particular, they cannot be interpreted as reflecting "visible" parental status effects such as wealth, which were already proxied to some extent by the measured demographic variables. They consist of all the influences on which brothers are "closer" to each other than a randomly drawn pair from the same population. But such influences include race, region, spatial proximity, similarity in the school system and peer groups of origin, similarity in the cultural environment, which includes influences which extend far beyond the original "family" boundaries, and similarity in subsequent environments. They should not be interpreted, except tautologically, as reflecting the force of family influences. They reflect the force of accidents of birth into a family, race, region, city, ethnic group, and more, and the fact that spatial and social mobility within half a generation is not perfect. Even with much mobility, people on average move only some distance from their original location in

\footnotetext{
${ }^{31}$ Michael made a similar comment at the Kinometrics conference (1977).
} 
geographic and social space. The correlation between brothers' earnings reflects this and should not be interpreted as being solely the effect of "family," or "class," nor as implying that there is no escape from ones "background." Note that all the background (and "foreground") measures taken together do not explain much more than about 30 percent of the observed variance of log earnings. If one were to make a major adjustment for the effect of transitory earnings, one would still be left with the conclusion that the inequality (opportunity?) within families is about as large as that between families. Whether the glass is half full or half empty depends on the point of view of the observer....

I have not tried to break down the family effect into "genetics" versus "environment," since even if were possible, it is not clear that it would give us any more handles on the problem without a fuller understanding of the mechanism by which these forces exert their influence. Some genetic differences might be corrigible (e.g., by enzymes), while for some environmental influences, such as cultural background, there are not effective intervention methods known.

Whether unmeasured common-to-brothers effects bias significantly the schooling coefficient is not clear. The direct evidence if ambiguous. If some weight is given to the possibility of errors of measurement and endogeneity of schooling, then much of the asserted bias disappears.

What good then are sibling data if by solving one problem (omitted familial variables) they aggravate other problems? While no panacea, they do provide us with a richer set of observational data and allow us to complicate our models and ask for more detailed answers. In econometric terms, they give us a larger set of instrumental 
variables, but only at the cost of explicit restrictions on the structure of our models.

Something more is learned, but as is often the case in science, much of what is learned extends the dimensions of the unknown (Griliches 1979, pp. S59-S60).

\section{Earning Functions - Maturity}

The early 80 s witnessed the subsidence of the ability-schooling controversy. In his survey for the Handbook of Labor Economics (1986), Willis when discussing the ability-bias, adopts the stand Griliches took in his summary of the 1979 survey:

"The literature surveyed can be characterized as ranging between two extreme positions, one saying that family effects are various and many and that they lead to serious overestimation solely from differences between siblings, preferably MZ twins. The other extreme would take the position that family effects work almost entirely via schooling and hence cause little bias in the estimate of its coefficient, and that the decline observed in within-sibling estimates is the result of the aggravation of other problems, such as errors in measurement and simultaneity and not the reflection of true family effects. The evidence at this point is ambiguous. Some sibling studies show little change in the schooling coefficient, some show much. The latter can be explained by reasonable rates of measurement error, but this the leaves the former unexplained. Unfortunately, data are not currently available which would allow the estimation of a metamodel nesting both of these positions within it." (Griliches 1979, pp. S81).

Willis himself expanded the simple ability-schooling model, when in his paper with Rosen (1979) he allowed for two different types of abilities. The model allowed for specialization according to comparative advantage, the person self-selecting into college and high school depending on his type of ability and rate of interest he faces. The Willis-Rosen model allows the estimation of both "ability-free" rates of return to schooling, and the sensitivity of college enrollment to wage differentials. In many 
respects it comes close to the model Griliches was outlining in his 1977 Presidential Address.

Subsequent research (Lillard, 1977) confirmed Hause's findings that the Griliches data were flawed because ability differences hardly show up at the early stages of one's work career and their effect on earnings becomes more pronounced only as the person grows older. This finding could not have caught Griliches by surprise, because, as we have seen, he was aware of the weakness of his data. On the other hand, the passage of time has shown him to be right on the effect of many of the latent variables that preoccupied him during the stormy $70 \mathrm{~s}$.

The analysis of twin data remained dormant for more than a decade. The inactivity was not due to exhaustion but due to the lack of new data. Then in 1994, fifteen years after the Sibling Survey, the "fight' was resumed. By now Griliches was out of the game, and his position was taken up by two newcomers to the field - Ashenfelter and Krueger (1994). Following Taubman and his collaborators, Ashenfelter and Krueger did not wait for the data to come to their doorstep, but went looking for it as the 1991 Twinsburg Twins Festival. Their results (1994) seemed to vindicate Griliches' assertions. Correcting for the measurement error in schooling, they find that previous estimates of the rate of return to schooling were downward biased. Their estimate (1216 percent) was twice as large as previous estimates and higher than the original estimates obtained when ability and measurement errors were not controlled for. Following Griliches they could not find a significant effect of ability on schooling, but that measurement errors in schooling introduce a significant downward bias in the rate 
of return estimate. ${ }^{32}$ The authors used the schooling of the twin reported by his brothers as an instrumental variable to correct for errors of measurement, and found that the corrected coefficient exceeds the standard "within" regression coefficient by over 80 percent!

Almost at the same time Behrman, Rosenzweig and Taubman (1994) published their most recent findings based on their new samples. The NAS-NRC Twins sample, used in their original study, was supplemented by the Minnesota Twin Registry. Their analysis was not confined to the effect of "natural endowments" on schooling and earnings, but was expanded to the marriage market, to explore the impact of endowments and schooling on assortive mating. The authors reiterate their previous conclusion that the rate of return to schooling is about 4 percent. Allowing for measurement errors in the schooling variable ( instrumenting the own reported schooling variable by the variable reported by the person's child) increases the estimate to 5 percent. The 30 percent bias was well bellow the Ashenfelter- Krueger estimate.

Subsequent rounds of the Twinsburg Twins sample have shown that Ashenfelter- Krueger first round results suffered from a sampling error. The June 1999

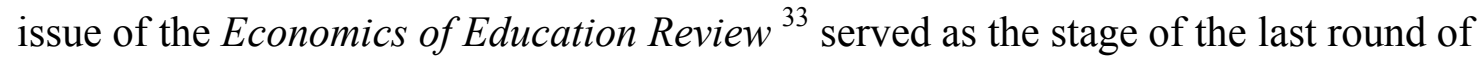
the twin controversy. Rouse (1999) summarized the results of the first four rounds of the Twinsburg sample. She finds a rate of return to schooling of 10 percent, but she also finds, using within twins regressions, that the standard cross-section OLS estimates suffer from a small upward bias (about 6 percent).

\footnotetext{
${ }^{32}$ The error component constituted about 10 percent of the measured variance of schooling - the estimate used by Griliches.
} 
Griliches' students extended his old stand: Neumark (1999) argued that the within-twin IV estimator amplifies the bias from any omitted ability difference between twins, relative to the standard within-twins estimator. Bound and Solon (1999) argued that one cannot relate to the schooling differential of the identical twins as exogenous. The differential in schooling in this case is clearly not random, and the within-twin estimation is vulnerable, therefore, therefore, to the same endogeneity bias as the cross-section estimates.

Behrman and Rosenzweig (1999) use a resurvey of the Minnesota twins to show that the upward bias in the OLS cross-section estimate is statistically significant. The authors are also careful to point out that the source of this bias need not be the direct effect of 'natural endowments' on schooling, but may originate from the correlation of this variable with other family characteristics that affect schooling, and, hence, may vary from one sample to the next. The reader cannot but notice that the authors' most recent estimate of the bias -12 percent- is almost exactly the size of the bias assumed by Griliches and by Becker, when they started this journey.

One of the first to follow Griliches' advice to incorporate a direct measure of school quality in the earnings function was Behrman. In his study with Birdsall (1983) of earnings in Brazil he uses the schooling level of the teachers as a measure of school quality. The authors argue that since quantity and quality of schooling are positively correlated (as assumed by Griliches and Mason), the omission of the quality variable leads to an upward bias in the estimate of the returns to years of schooling, and can explain in many cases the observed differential in the rate of return among individuals,

\footnotetext{
${ }^{33}$ A journal that did not even exist at the time of the first round of this controversy.
} 
and between different regions. From a policy point of view the investment in school quality may yield higher returns than those from investing in quantity.

The 90s witnessed a reawakening of interest in this issue. In their survey Card and Krueger (1996) tend to confirm Griliches' assertion - school resources have a positive effect on future income, but they are careful to warn that the evidence is not always conclusive. Griliches assumed that the quality effect is additive (see equation 4). In the Card and Krueger mode ${ }^{34}$ the effect is more complex: it increases the slope of the schooling-earning gradient (since each year of schooling "produces" more human capital, the higher the school's quality), but it may also affect the intercept (because of self-selection - students attending better schools decide to invest more in schooling). Reduced form regressions show that a 10 percent increase in school resources increase the future income of students by $0.4-1.1$ percent.

The Presidential Address in 1975 played an important role in highlighting the importance of the simultaneity problem in the estimation of the rate of return to schooling. Griliches traced the simultaneity to ability and expected earnings affecting actual earnings, while affecting also schooling demand. Subsequent research returned to the structural equations framework outlined in Becker's Woytinsky Lecture (1967). Several studies tried to identify this structure of demand and supply of schooling by using institutional features of the education system (for example, distance to college) as identifiers of the demand side, and as instruments in the estimation of the abilityschooling interaction. On the $23^{\text {rd }}$ anniversary of Griliches' Presidential Address,

\footnotetext{
${ }^{34}$ The Card- Krueger model is very similar to that used by Behrman and Birdsall (1983).
} 
David Card delivered the Fisher-Schultz Lecture at the 1998 Meeting of the European Econometric Society. In his lecture, he summarized these attempts (2001):

"A supply and demand framework leads to a somewhat richer econometric model for schooling and earnings than is usually adopted in the applied literature. In particular, the implied data generation process for earnings has both a random intercept (reflecting differences across individuals in the amount they could earn at every level of schooling) and a random education slope (reflecting differences across individuals in the marginal return to education). Although one can still estimate a standard human capital earnings function by standard OLS or IV methods, the parameter estimates must be interpreted carefully. Even IV estimation based on ideal instruments (observable factors that are by assumption independent of individual abilities) will typically recover a weighted average of returns to education for people whose education choices were affected by the instrument, rather than the average marginal return to education in the population.

The recent literature that uses supply-side features to instrument schooling choices tends to find IV estimates of the return to schooling that at least as big and sometimes substantially bigger than the corresponding OLS estimates. In many cases the IV estimates are relatively imprecise, and none of the empirical strategies is based on true randomization. Thus, no individual study is likely to be decisive in the debate over the magnitude of ability biases in OLS estimates of the return to schooling. Taken as a whole, however, the findings from the recent IV literature are remarkably consistent with Griliches' (1977) assessment of a much earlier set of studies, and point to a causal effect of education that is as big or bigger than the OLS estimated return, 
at least for whose schooling choices are affected by the supply-side innovations that have been studies so far.” (2001, p. 1158).

Griliches was aware of the limitations of the panel data he was using, and in his Presidential Address he expressed his hope that "Advantage should be taken of the time series nature of the various survey panels that have become available. All of the studies mentioned, including my own, have yet to approach such data from a truly dynamic point of view" (1977, p.17). Wolpin and the "structural empiricists" took up this challenge. The "structuralists" combined the Willis-Rosen comparative advantage model (1979) with a Mortensen-style search model to create a complex model describing the sequential schooling- market work decision. According to this approach, the parameters of the wage function are affected not merely by the skill production function, but also by the search technology and the opportunity cost of time ${ }^{35}$

\section{E. Summary - Zvi Griliches' Contribution to the Theory of Human Capital}

At the turn of the millennium Jacob Mincer's earning function is alive and well.

Attesting to its robust health is the extensive discussion of the increasing earning differentials in the U.S. and U.K. in the 90s that was conducted fully in the vernacular of the Human Capital Theory ${ }^{36}$. The ability-schooling controversy is by now part of the history of economic thought.

\footnotetext{
${ }^{35}$ For a recent summary of this literature see Wolpin (2003).

${ }^{36}$ For a summary of this literature see the survey by Katz and Autor in The Handbook of Labor Economics (1999).
} 
At the end of the day one may ask: what was Zvi Griliches' contribution to the flourishing of this field? At the outset we had to admit that Griliches did not contribute to the development of the theory. His forte' was in measurement. He and his collaborators brought to the field a set of new econometric tools, which allowed more precise answers to the problem. As a result we have gained a better understanding of the role of unobservables in the schooling-earning interaction. Ironically, Griliches may have entered the field prematurely. There was a jarring gap between the crudeness of his data and the sophistication of his econometric tool-kit. The data that could show his virtuosity were, unfortunately, in the hands of his "opponents." As a result Griliches' role was confined to repelling the opponents' attack. In this position he had no rival. The forefathers of the earning-function did not seem to share the feeling of "crisis". Becker was basically a theorist, and his discussion of empirical results in the Theory of Human Capital (1964) was an exception, rather than the rule. Mincer was preoccupied with his own research agenda, and was never disturbed by critics. At the time none of the younger labor economists had the reputation of Griliches. So it fell to him (with the aid of Goldberger) to face the "onslaught". His penetrating analysis of his opponents' data and methodology pointed out the loopholes in their seemingly foolproof arguments. Though he lacked the appropriate data, most of his assertions have proven to be correct.

Blaug concludes his 1976 survey paper:

"Nothing is easier than predicting the future course of scientific development - and nothing is more likely to be wrong. Nevertheless, let me rush in where angels fear to tread. In all likelihood, the human-capital research program will never die, but it will gradually fade away to be swallowed up by the new theory of signaling, the theory of how employees, and indeed all buyers and sellers select each other when their attributes 
matter but when information about these attributes is subject to uncertainty. In time, the screening hypothesis will be seen to have marked a turning point in the "human investment revolution in economic thought," a turning point to a richer, still more comprehensive view of the sequential lifecycle choices of individuals." (1976, p. 850).

Griliches' timely intervention was crucial in turning the tide. Once again it was shown that economic forecasting should be left to the angels!

As I come to the end of this survey I would like to introduce a personal note. The reader of this survey may be left with a lingering puzzle: What led Zvi, who was, after-all, interested in the measurement of the social contribution of "knowledge" to economic growth, to devote a decade of his research to a problem whose main implications relate to the private returns of education? I don't think that Zvi took up the fight to defend the purity of econometric identification methods, or to impress his readers with a new elegant recursive model. He took up the fight because he was an ardent believer that (as he put it) "our findings concerning the earnings functions (of siblings and others) should not be interpreted as being solely the effect of "family" vs “class," nor as implying that there is no escape from one's "background". " Zvi, the immigrant who arrived on the shores of Palestine at the age of 17 with no "background," and who later arrived in the U.S. with only the human capital he accumulated in a crash program in Israel to his name, truly believed schooling was the main channel for social and economic mobility. 
In his interview with Krueger and Taylor (2000) Zvi was asked about the concluding section of his Presidential Address citing The House of Pooh Corner. ${ }^{37}$ But if I had to remember Zvi for this paper, I would not have cited A.A. Milne but rather Zvi's own words:" It is a sad fact that in doing empirical work we must continuously search for the passage between the Scylla of biased inferences due to left out and confounded influences, and the Charybdis of overzealously purging our data of most of their identifying variance, being left largely with noise and error in our hands." I believe that this is the way Zvi wanted us to remember him, as a Ulysses, in his sailor's cap, who took the helm of the boat at a critical moment to navigate it to quieter waters. He stopped at the Island of Human Capital for ten years, only to continue his long voyage home.

37"How would it be," said Pooh slowly, "if, as soon as we're out of sight of this Pit, we try to find it again?"

"What's the good of that? Said Rabbit.

"Well, said Pooh, "we keep looking for Home, and not finding it, so I thought that if we looked for this Pit, we'd be sure not to find it, which would be a Good Thing, because then we might find something that we weren't looking for, which might be just what we were looking for, really."

"I don't see much sense in that," said Rabbit.

"No," said Pooh humbly, "there isn't. But there was going to be when I began it. It's just that something happened to it on the way." A.A. Milne, The House at Pooh Corner 
References:

Ashenfelter, Orley and Alan B. Krueger (1994), "Estimates of the Economic Return to Schooling from a New Sample of Twins," American Economic Review, 84(5): 115773.

Ashenfelter, Orley and Joseph D. Mooney (1968), "Graduate Education, Ability and Earnings." Review of Economics and Statistics, 50: 78-86.

Becker, Gary S. (1960), "Underinvestment in College Education," American Economic Review, 50 (Proceedings): 346-54.

(1967), "Human Capital and the Personal Distribution of Income," Woytinski Lecture No. 1. Ann Arbor: University of Michigan Press.

(1964), Human Capital, 1st ed. New York: Natural Bureau of

Economic Research.

Behrman, Jere T., Paul Taubman, Terrence Wales and Zdenek Hrubec (1980), Socioeconomic Success: A Study of the Effects of Genetic Endowment, Family Endowment, and Schooling, Amsterdam: North- Holland.

Behrman, Jere T., and Nancy Birdsall (1983), “The Quality of Schooling”, American Economic Review, 73 (5):928-946.

Behrman, Jere T., Mark R. Rosenzweig, and Paul Taubman (1994), "Endowments and the Allocation of Schooling in the Family and the Marriage Market: the Twins Experiment", The Journal of Political Economy, 102 (6): 1131-1174.

Behrman, Jere T., Mark R. Rosenzweig (1999), “ “Ability’ Biases in Schooling Returns and Twins: a Test and New Estimates", Economics of Education Review, 18 (2):159-167.

Ben-Porath, Y. (1967), "The Production of Human Capital and the Life Cycle of Earnings," Journal of Political Economy, 75: 352-365.

Blank, D.M. and G.J. Stigler (1957), The Demand and Supply of Scientific Personnel, Princeton.

Blaug, Mark (1976), "The Empirical Status of Human Capital Theory: A Slightly Jaundiced Survey," Journal of Economic Literature, 14: 827-55. 
Bound John, and Gary Solon (1999), "Double Trouble: on the Value of Twin-Based Estimation of the Returns to Schooling", Economics of Education Review, 18 (2):169182.

Card, David (1999), "The Causal Effect of Education on Earnings," in O.C. Ashenfelter and D. Card, eds. Handbook of Labor Economics, Vol. III.

(2001), "Estimating the Returns to Schooling: Progress on some Persistent Econometric Problems", Econometrica,69 (5): 1127-1160.

and Alan B. Krueger (1996), "School Resources and Student Outcomes: An Overview of the Literature and New Evidence from North and South Carolina," Journal of Economic Perspectives, 10 (4):31-50.

Chamberlain, G. (1975), "Unobservables in Econometric Models," unpublished Ph.D. dissertation, Harvard University, Cambridge, MA.

Clark, H.F. (1937), Life Earnings in Selected Occupations in the United States, New York.

Dension, Edward F. (1962), The Sources of Economic Growth in the United States and the Alternatives before Us. Supplementary Paper No. 13. New York: Committee Economic Development.

(1964), "Measuring the Contribution of Education," In The Residual Factor and Economic Growth, pp. 13-55, 77-100. Paris: Organization Economic Co-operation and Development.

Friedman, M. and S. Kuznets (1945), Income from Independent Professional Practice, New York: NBER.

Gorseline, Donald E. (1932), The Effect of Schooling upon Income, Bloomington: Graduate Council, Indiana University.

Griliches, Zvi (1957),"Hybrid Corn: An Exploration in the Economics of Technological Change," Econometrica,. 25(4): 501-522.

(1958),"Research Cost and Social Returns: Hybrid Corn and Related Innovations," Journal of Political Economy, 66(5): 419-431.

(1963a),"Estimates of the Aggregate Agricultural Production Function from Cross- Sectional Data," Journal of Farm Economics, 45(2): 419-428.

(1963b), "The Sources of Measured Productivity Growth: U.S. Agriculture, 1940- 1960," Journal of Political Economy, 71(4): 331-346. 
(1964),"'Research Expenditures, Education, and the Aggregate Agricultural Production Function," American Economic Review, 64(6): 961-974.

(1967), "Production Functions in Manufacturing: Some Preliminary Results," in M. Brown, ed., The Theory and Empirical Analysis of Production, NBER, Studies in Income and Wealth, New York: Columbia University Press, Vol. 31: 275340 .

(1968), "Production Functions in Manufacturing: Some Additional Results," Southern Economic Journal, 35(2): 151-156.

(1970), "Notes on the Role of Education in Production Functions and Growth Accounting," in W. Lee Hansen, editor, Education, Income and Human Capital, NBER, Studies in Income and Wealth, New York: Columbia University Press, Vol. 325. 84(4), part 2: S69-S85.

(1976), "Wages of Very Young Men," Journal of Political Economy, (1977), "Estimating the Returns to Schooling: Some Econometric Problems," Econometrica, 45(1): 1-22.

(1979), "Sibling Models and Data in Economics: Beginnings of a Survey," Journal of Political Economy, 87(5), Part 2: S37-S64.

(1997) "Education, Human Capital, and Growth- A Personal Perspective", paper presented at the Memorial Conference for Yoram Ben-Porath, Jerusalem, October 1993; Journal of Labor Economics , 15(1), part 2: S330-S344.

, John Bound and Bronwyn H. Hall (1986), "Wages, Schooling and IQ of Brothers and Sisters: Do The Family Factors Differ?", International Economic Review, 27(1): 77-105.

and Gary Chamberlain (1975), "Unobservables with a VarianceComponents Structure: Ability, Schooling and the Economic Success of Brothers", International Economic Review, , 16(2): 422-449.

(1977),"More on Brothers," in Paul Taubman, ed., Kinometrics:

Determinants of Socioeconomic Success Within and Between Families, New York: North Holland.

and Dale Jorgenson (1966), "Sources of Measured Productivity Change: Capital Input, American Economic Review, 56(2): 50-61. 
Studies, 34(3): 249-283.

(1967), "The Explanation of Productivity Change," Review of Economic and William Mason (1972), "Education, Income, and Ability," Journal of Political Economy,80(3), Part II: S74-S103.

Goldberger, Arthur S. (1977), "Twin Methods: A Skeptical View”, in Paul Taubman, ed., Kinometrics: Determinants of Socioeconomic Success Within and Between Families, New York: North Holland.

Hansen, W. Lee, Burton A. Weisbrod and W.J. Scanlon (1970), "Schooling and Earnings of Low Achievers", American Economic Review, 60: 409-418.

Hause, John, C. (1972), "Earnings Profile: Ability and Schooling," Journal of Political Economy,80(3), Part II: S108-S138.

Houthakker, H.S. (1959), "Education and Income," Review of Economics and Statistics, 41: 21-28.

Husen, T. (1968), “Talents, Opportunity, and Career: A 26 Year Follow-up”, School Review, 76 (4).

Jensen, Arthur R. (1967), "Estimating the Limits of Hereditability of Traits by Comparison of Monozygotic and Dizygotic Twins", Proceedings of the National Academy of Science, 58:149-156.

Juster, F. Thomas (1975), “Introduction and Summary" to F.T. Juster ed., Education, Income and Human Behavior, New York: McGraw-Hil: 1-43.

Katz Lawrence F. and David H Autor.(1999), "Changes in the Wage Structure and Earnings Inequality," in O.C. Ashenfelter and D. Card, eds. Handbook of Labor Economics Vol. III.

Kerr, Clark (1975), “Foreward” to F.T. Juster ed., Education, Income and Human Behavior, New York: McGraw-Hil: xv-xvi.

Krueger, Alan B. and Timothy Taylor (2000), “An Interview with Zvi Griliches”, The Journal of Economic Perspectives, 14 (2):171-190.

Lillard, Lee (1977), "Inequality: Earnings vs. Human Wealth", American Economic Review, 67: 42-53.

Michael, Robert T. (1977), "Family Background and Achievement: A Comment" in Paul Taubman, ed., Kinometrics: Determinants of Socioeconomic Success Within and Between Families, New York: North Holland. 
Miller, H.P. (1960), “Annual and Lifetime Income in Relation to Education,” American Economic Review 50: 962-986.

Mincer, Jacob (1958), "Investment in Human Capital and Personal Income Distribution," Journal of Political Economics, 66: 281-302.

(1962), "On-the-Job Training: Costs, Returns, and Some Implications," Journal of Political Economics, 70(5) Part 2: 50-79.

(1974), Schooling, Experience and Earnings, New York: Natural Bureau of Economic Research.

Neumark, David (1999), "Biases in Twin Estimates of the Return to Schooling”, Economics of Education Review, 18 (2):143-148.

Parsons, Donald, O. (1972), "Specific Human Capital: An Application to Quit Rates and Layoff Rates," Journal of Political Economics, 80(6): 1120-43.

Riley, John G. (1975) “Competitive Signaling”, Journal of Economic Theory, 10:175186.

(1979) "Testing the Educational Screening Hypothesis", Journal of Political Economy, 87: S227-S251.

Rosen, Sherwin. (1977), "Human Capital: A Survey of Empirical Research," in R. Ehrenberg, ed., Research in Labor Economics. Greenwich Conn.: JAI Press, Vol.1.

Rouse, Cecilia E. (1999), “Further Estimates of the Economic Return to Schooling from a New Sample of Twins", Economics of Education Review, 18 (2):169-182.

Schultz, Theodore W. (1961), "The Investment in Human Capital”, American Economic Review, 5 (1): 1-17.

Spence, Michael (1973), "Job Market Signaling," Quarterly Journal of Economics, 87(3): 355-74.

(1974), Market signaling. Cambridge: Harvard University Press.

Stiglitz, Joseph E. (1975), "The Theory of 'Screening', Education and the Distribution of Income," American Economic Review, 65(3): 283-300. 
Taubman, Paul (1976), “The Determinants of Earnings: Genetics, Family, and Other Environments: A Study of White Male Twins," American Economic Review 66: 858870.

and Terence Wales (1974), Higher education and earnings: College as an investment and a screening device. New York: McGraw-Hill.

(1975), "Education as an Investment and a Screening Device", in F.T. Juster ed., Education, Income and Human Behavior, New York: McGraw-Hil: 95-121.

Thorndike, R.L. and E. Hagen (1959), Ten Thousand Careers, New York: John Wiley and Sons.

Willis, Robert J. (1986), "Wage Determinants: A Survey and Reinterpretation of Human Capital Earnings Functions," in O.C. Ashenfelter and R. Layard, eds. Handbook of Labor Economics Vol. I. and Sherwin Rosen (1979), "Education and Self-Selection," Journal of Political Economy, 87(5), Part 2: S7-S36.

Wolpin, Kenneth I. (2003), "Wage Equations and Education Policy," in M. Dewatripont, S. Turnovsky and L.Hansen eds., Advances in Economics and Econometrics, Cambridge University Press: Cambridge. 